\title{
Relationship between BMI and adiposity among different ethnic groups in 2-year-old New Zealand children
}

\author{
Mariam J. Buksh ${ }^{1,2}$, Joanne E. Hegarty ${ }^{1,2}$, Rebecca Griffith ${ }^{3}$, Jane M. Alsweiler ${ }^{1,3}$, Chris J. McKinlay ${ }^{2,3,4}$ and \\ Jane E. Harding ${ }^{2}$ for the hPOD Study Team \\ ${ }^{1}$ Newborn Service, Starship Child Health, Auckland City Hospital, Private Bag 92024, Auckland Mail Centre, Auckland 1142, \\ New Zealand \\ ${ }^{2}$ Liggins Institute, University of Auckland, Private Bag 92019, Victoria Street West, Auckland 1142, New Zealand \\ ${ }^{3}$ Department of Paediatrics: Child and Youth Health, University of Auckland, Level 12, Support Building, Auckland City \\ Hospital, 2 Park Road, Grafton, Auckland 1023, New Zealand \\ ${ }^{4}$ Kidz First, Middlemore Hospital, Private Bag 93311, Otahubu, Auckland 1640, New Zealand
}

(Submitted 2 July 2018 - Final revision received 27 October 2018 - Accepted 7 December 2018 - First published online 13 February 2019)

\section{Abstract}

Age- and sex-based BMI cut-offs are used to define overweight and obesity, but the relationship between BMI and body composition has not been very well studied in children or compared between children of different ethnic groups. Body size and composition in childhood are also influenced by size at birth. Our aim was to compare body size and composition at 2 years in children with different ethnicity and size at birth. We prospectively followed a multi-ethnic cohort of 300 children born with risk factors for neonatal hypoglycaemia (infants of diabetics, large or small at birth or late preterm) to 2 years corrected age. Complete data on weight, height and head circumference and body composition using bioelectrical impedance $24 \pm 1$ months corrected age were available in 209 children. At birth, compared with European children, Chinese, Indian and other ethnicity children were lighter, and Indian children had smaller head circumferences, but birth lengths were similar in all ethnic groups. At 2 years, Pacific children were heavier and had higher BMI $z$ scores, and Indian children had smaller head circumferences and lower BMI $z$ scores than those from other ethnic groups. However, fat mass and fat-free mass indices were similar in all groups. At median BMI, fat mass:fat-free mass ratio was $23 \%$ lower in Pacific than in Indian children $(0 \cdot 22 v \cdot 0 \cdot 27, P=0 \cdot 03)$. BMI is not a good indicator of adiposity in this multi-ethnic cohort of 2-year-old New Zealand children.

\section{Key words: Obesity diagnosis: Anthropometry: Body composition: Physiology: Body weight}

Overweight and obesity in childhood are not the same as overweight and obesity in adulthood. In adults, the BMI cut-offs used to define overweight and obesity are based on fixed values of 25 and $30 \mathrm{~kg} / \mathrm{m}^{2}$, respectively, which have been shown to be associated with increased adiposity resulting in adverse health consequences ${ }^{(1)}$. In children, body fatness varies according to age and sex, and therefore overweight and obesity are defined on the basis of age- and sex-specific BMI cutoffs $^{(2,3)}$. The ideal definition of overweight and obesity, however, would be based on body fatness, but this is not practical to measure in clinical settings. Increased fatness and central fat distribution are associated with adverse blood lipid concentrations and blood pressure in children, as in adults ${ }^{(4,5)}$. Although children with very high BMI are likely to have high body fat, children who are overweight may have an excess of lean mass as the cause of their increased weight for height ${ }^{(6)}$. Thus, BMI may not be a reliable measurement of body composition for the purposes of health screening in children.
Further, differences in body composition have been reported in infants and children of different ethnicities. For example, South Asian infants had greater fat mass (FM) and less fat-free mass (FFM) than infants of European ethnicity at 6-12 weeks of age $^{(7)}$, and this difference, including preservation of body fat, has been shown to persist into childhood ${ }^{(8)}$. A New Zealand study looking at body composition using dualenergy X-ray absorptiometry scanning in 2-year-old children whose mothers had gestational diabetes also showed Indian boys had more central and abdominal fat compared with European boys ${ }^{(9)}$.

Size at birth also affects weight gain in infancy, childhood and adulthood $^{(10,11)}$, and heavier birth weight is strongly associated with increased risks of overweight and obesity in adult$\operatorname{hood}^{(12,13)}$. However, size at birth is affected by ethnicity ${ }^{(14,15)}$ regardless of maternal country of birth and socio-economic status, as shown by the persisting lower birth weight among offspring of South Asian migrants to the $\mathrm{UK}^{(16)}$.

Abbreviations: BIA, bioelectrical impedance analysis; FFM, fat-free mass; FFMI, fat-free mass index; FM, fat mass; FMI, fat mass index; hPOD, hypoglycaemia Prevention with Oral Dextrose.

* Corresponding author: Professor Jane E. Harding, email j.harding@auckland.ac.nz 
Auckland, the largest city in New Zealand, has a large and ethnically diverse population living in the same geographical region. According to the 2013 census data, 59\% of the population self-identified as European, $23 \%$ as Asian, $15 \%$ as Pacific and $11 \%$ as Māori, with the remainder being made up of people of other smaller ethnic groups ${ }^{(17)}$. The relationship between BMI and body composition in young children of such an ethnically diverse population has not previously been reported.

\section{Aim}

The primary aim of our study was to determine the relationship between birth weight, BMI and body composition at 2 years corrected age in New Zealand children of different ethnic groups.

\section{Methods}

Participants in this study were born at risk of neonatal hypoglycaemia and were recruited at birth into the pre-hPOD (hypoglycaemia Prevention with Oral Dextrose) trial, a multicentre randomised placebo-controlled trial investigating the efficacy of different doses of $40 \%$ dextrose gel for prevention of hypoglycaemia ${ }^{(18)}$. The trial took place at Auckland City Hospital and Waitakere Hospital, Auckland, New Zealand, from August 2013 to November 2014. Babies were eligible for randomisation if they were at risk of hypoglycaemia: infant of diabetic mother, preterm ( $<37$ weeks' gestation), small $(<2.5 \mathrm{~kg}$ or $<10$ th centile on customised or population weight charts) or large $(>4.5 \mathrm{~kg}$ or $>90$ th centile on customised or population weight charts) and fulfilled all of the following: $\geq 35$ weeks' gestation, birth weight $>2 \cdot 2 \mathrm{~kg},<1 \mathrm{~h}$ of age, no apparent indication for admission to Neonatal Intensive Care Unit (NICU) at the time of randomisation, unlikely to require NICU admission for any other reason, and mother intending to breastfeed. Babies with a major congenital abnormality, history of formula feed or intravenous fluid administration, already diagnosed with hypoglycaemia or admission to NICU were excluded.

All children were eligible for follow-up at $24 \pm 1$ months corrected age. As part of a more extensive multidisciplinary assessment, anthropometric measurements were undertaken by trained assessors in the following sequence: weight, height, head circumference and bioelectrical impedance analysis (BIA). Weight was measured using electronic scales to the nearest $0 \cdot 1 \mathrm{~kg}$, with the child dressed in minimal clothing. Height was measured using a wall-mounted stadiometer to the nearest $0 \cdot 1 \mathrm{~cm}$ with the child in bare feet or socks. Head circumference was measured at the maximal occipitofrontal circumference with a nonstretchable tape to the nearest $0 \cdot 1 \mathrm{~cm}^{(19)}$. Percentile and $z$ scores were calculated from the New Zealand-WHO growth charts ${ }^{(19)}$.

BIA was carried out using an ImpSFB7 body composition analysis device (ImpediMed Ltd), using tetra-polar leads attached to four self-adhesive skin electrodes on the right hand and foot with the child semi-reclining or supine. BIA estimates FFM and FM by measuring the body's opposition to the flow of a constant alternating current known as impedance $(Z)$. Impedance is due to electrical resistance of tissue fluids $(R)$ and
Table 1. Baseline characteristics of children and their mothers ( $n 300$ ) (Mean values and standard deviations; medians and ranges; numbers and percentages)

\begin{tabular}{|c|c|c|c|}
\hline & Mean & & SD \\
\hline Maternal age (years) & 32.5 & & $5 \cdot 6$ \\
\hline \multicolumn{4}{|l|}{ Maternal BMI $\left(\mathrm{kg} / \mathrm{m}^{2}\right)$} \\
\hline Median & \multicolumn{3}{|c|}{$27 \cdot 4$} \\
\hline Range & \multicolumn{3}{|c|}{$17 \cdot 6-66 \cdot 0$} \\
\hline \multicolumn{4}{|l|}{ Maternal parity } \\
\hline Median & \multicolumn{3}{|c|}{2} \\
\hline Range & \multicolumn{3}{|c|}{$0-10$} \\
\hline \multicolumn{4}{|l|}{ NZDep score* } \\
\hline Median & \multicolumn{3}{|c|}{6} \\
\hline Range & \multicolumn{3}{|c|}{$1-10$} \\
\hline \multicolumn{4}{|l|}{ Mode of delivery } \\
\hline \multicolumn{4}{|l|}{ Normal vaginal delivery } \\
\hline$n$ & \multicolumn{3}{|c|}{129} \\
\hline$\%$ & \multicolumn{3}{|c|}{43} \\
\hline \multicolumn{4}{|l|}{ Emergency caesarean section } \\
\hline$n$ & \multicolumn{3}{|c|}{68} \\
\hline$\%$ & \multicolumn{3}{|c|}{23} \\
\hline \multicolumn{4}{|l|}{ Instrumental delivery } \\
\hline$n$ & \multicolumn{3}{|c|}{31} \\
\hline$\%$ & \multicolumn{3}{|c|}{10} \\
\hline \multicolumn{4}{|l|}{ Elective caesarean section } \\
\hline$n$ & \multicolumn{3}{|c|}{72} \\
\hline$\%$ & \multicolumn{3}{|c|}{24} \\
\hline \multirow{2}{*}{\multicolumn{4}{|c|}{$\begin{array}{l}\text { Risk factors for hypoglycaemiat } \\
\text { Infant of diabetic mother }\end{array}$}} \\
\hline & & & \\
\hline$n$ & \multicolumn{3}{|c|}{209} \\
\hline$\%$ & \multicolumn{3}{|c|}{$69 \cdot 7$} \\
\hline Preterm & & & \\
\hline$n$ & & 32 & \\
\hline$\%$ & & $10 \cdot 6$ & \\
\hline Small & & & \\
\hline$n$ & & 56 & \\
\hline$\%$ & & $18 \cdot 7$ & \\
\hline Large & & & \\
\hline$n$ & & 45 & \\
\hline$\%$ & & $15 \cdot 0$ & \\
\hline Gestational age (week) & 37.9 & & $1 \cdot 1$ \\
\hline Birth weight $(\mathrm{g})$ & 3257 & & 621 \\
\hline Birth weight $z$ score & 0.20 & & 1.31 \\
\hline Length $(\mathrm{cm})$ & $50 \cdot 5$ & & $2 \cdot 6$ \\
\hline Length $z$ score & 0.25 & & 0.95 \\
\hline Head circumference $(\mathrm{cm})$ & 34.6 & & 1.7 \\
\hline Head circumference $z$ score & 0.31 & & 1.32 \\
\hline
\end{tabular}

NZDep, New Zealand Deprivation.

* The NZDep 2013 score which was based on the home address of the participant at the time of the study is a measure of socio-economic status of the population and is derived from 2013 census data. It is measured on a decile scale from 1 to 10 , with 1 representing the areas with the least deprived scores and 10 the most deprived scores $^{(24,25)}$.

† Some children had more than one risk factor for hypoglycaemia.

capacitive reactance from cell membrane capacitance $\left(X_{\mathrm{c}}\right)^{(20)}$. FFM is estimated from total body water, which in turn is estimated from resistance parameters. The ImpSFB7 employs bioelectrical impedance spectroscopy, which involves measurement of impedance across 256 logarithmically spaced frequencies in the range $3-1000 \mathrm{kHz}$. Cole modelling of impedance data and mixture theory is used to calculate FFM, and FM is determined from the difference between total mass and FFM. We used the automated FFM and FM values based on the manufacturer's proprietary calculations, which account for sex, height and weight. Two measurements were obtained, with a third recorded if variation in percentage FM was $>1 \%$, and mean values were used in analysis. Body fat and fat-free 
measurements in this age group using ImpediMed devices have shown close relationship with reference methods such as dualenergy X-ray absorptiometry ${ }^{(21)}$.

Body composition percentages and indices were then calculated using the following formulae: $\mathrm{FM}$ percentage $=(\mathrm{FM} /$ $(\mathrm{FM}+\mathrm{FFM})) \times 100$; fat-free (lean) mass percentage $=(\mathrm{FFM} /$ $(\mathrm{FM}+\mathrm{FFM})) \times 100$; fat mass index $(\mathrm{FMI})\left(\mathrm{kg} / \mathrm{m}^{2}\right)=\mathrm{FM}(\mathrm{kg}) /$ height $(\mathrm{m})^{2}$ and fat-free mass index $($ FFMI $)=$ FFM $(\mathrm{kg}) /$ height $(\mathrm{m})^{2(22)}$. Ethnicity was self-identified by parents and caregivers at the 2-year assessment and was prioritised, according to New Zealand health sector protocol ${ }^{(23)}$.

\section{Statistical analysis}

Data were analysed using JMP version 12.1.0 (SAS Institute). Groups were compared using $\chi^{2}$ tests or ANOVA with Tukey post hoc corrections for multiple comparisons. Linear standard least squares and logistic regression models were used to examine the relationship between variables. For comparison between ethnic groups, birth data were adjusted for risk factors for hypoglycaemia and maternal BMI at the time of booking for antenatal care, and 2-year anthropometry and body composition data were adjusted for the potential mediators: birth size, gestation, risk factors for hypoglycaemia and maternal BMI. Data are presented as number (percentage), mean (standard deviation), median (range) and $\beta$ coefficient (95\% CI).

\section{Ethics approval}

Ethics approval was obtained from the New Zealand Health and Disability Ethics Committee for the pre-hPOD Study (HDEC Ref 13/NTA/8) and for the follow-up study (HDEC Ref 15/STH/97). Written informed consent was obtained from parents or caregivers for the neonatal study and again at follow-up.

\section{Results}

A total of 415 infants were recruited into the pre-hPOD study. A convenience sample of first 300 children assessed at 2 years corrected age is included in this report. The baseline characteristics of the children who were assessed are presented in Table 1. Of the 300 children included in the study, 209 completed both auxology and body composition assessments.

Children of mothers with diabetes in pregnancy as their risk factor for hypoglycaemia made up almost $70 \%$ of the cohort, with the proportion varying from $54 \%$ in European to $92 \%$ in Indian children (Table 2). There was only one Indian and one Chinese child (each 3\%) with preterm as a risk factor, and only three children in each of these groups ( 8 and $10 \%$, respectively) with large size at birth as a risk factor for hypoglycaemia. European children were more likely to have small (26\%) or large $(21 \%)$ as risk factors, and Maori children were also more likely to have large as a risk factor (23\%).

At birth, compared with European children, Chinese, Indian and other children were lighter, and Indian children had smaller head circumferences, but birth lengths were similar in all ethnic groups (Table 3).

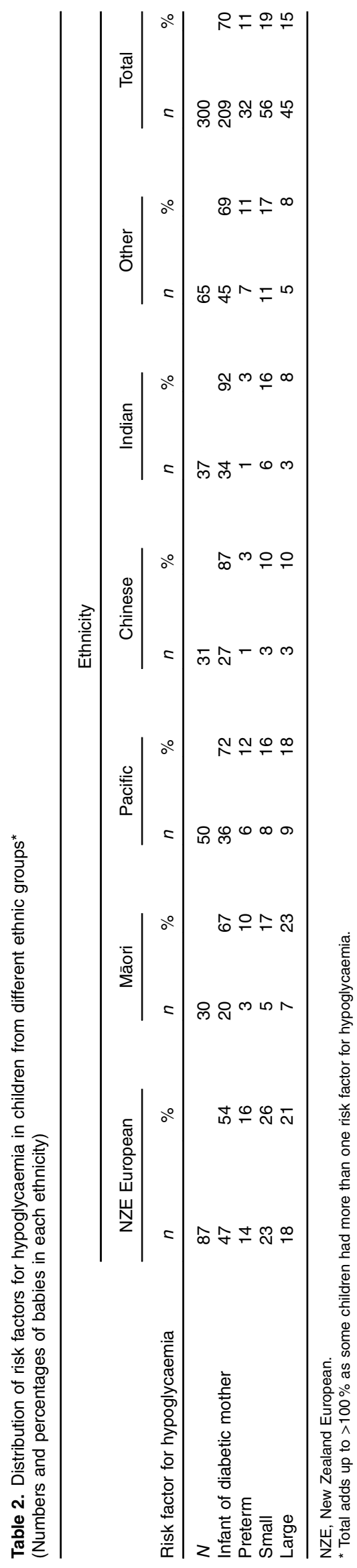


Table 3. Anthropometry and body composition in children from different ethnic groups* (Mean values and standard deviations)

\begin{tabular}{|c|c|c|c|c|c|c|c|c|c|c|c|c|c|c|}
\hline & \multicolumn{2}{|c|}{ NZE $(n 87,29 \%)$} & \multicolumn{2}{|c|}{ Māori (n 30, 10\%) } & \multicolumn{2}{|c|}{ Pacific $(n 50,17 \%)$} & \multicolumn{2}{|c|}{ Chinese ( $n 31,10 \%)$} & \multicolumn{2}{|c|}{ Indian ( $n 37,12 \%)$} & \multicolumn{2}{|c|}{ Other $(n 65,22 \%)$} & \multirow[b]{2}{*}{$P$} & \multirow[b]{2}{*}{$P$ adjusted $\sharp$} \\
\hline & Mean & SD & Mean & SD & Mean & SD & Mean & SD & Mean & SD & Mean & SD & & \\
\hline \multicolumn{15}{|l|}{ Birth anthropometry } \\
\hline Weight $(\mathrm{g})$ & $3339^{\mathrm{a}}$ & 726 & $3440^{a, b, c}$ & 716 & $3453^{a, b}$ & 458 & $3130^{b, c}$ & 458 & $3012^{c}$ & 375 & $3111^{b, c}$ & 475 & $<0.001$ & $<0.001$ \\
\hline Weight $z$ score & $0.43^{\mathrm{a}}$ & 1.47 & $0.73^{\mathrm{a}, \mathrm{b}, \mathrm{c}}$ & 1.50 & $0.71^{a, b}$ & 1.33 & $-0.21^{b, c}$ & 0.91 & $-0.41^{\mathrm{c}}$ & 0.87 & $-0.21^{b, c}$ & 1.02 & $<0.001$ & $<0.001$ \\
\hline Length $(\mathrm{cm})$ & $50 \cdot 6^{\mathrm{a}}$ & $2 \cdot 7$ & $51 \cdot 1^{\mathrm{a}}$ & 3.2 & $50 \cdot 7^{\mathrm{a}}$ & $2 \cdot 7$ & $50 \cdot 7^{\mathrm{a}}$ & 1.7 & $49.8^{\mathrm{a}}$ & $2 \cdot 2$ & $50 \cdot 1^{\mathrm{a}}$ & 2.6 & $<0.001$ & 0.31 \\
\hline Length $z$ score & $0.35^{a}$ & 0.94 & $0.58^{\mathrm{a}}$ & 1.15 & $0.38^{\mathrm{a}}$ & 0.93 & $0.24^{a}$ & 0.68 & $-0.06^{a}$ & 0.83 & $0.07^{\mathrm{a}}$ & 0.99 & $<0.001$ & 0.21 \\
\hline Head circumference $(\mathrm{cm})$ & $34 \cdot 6^{\mathrm{a}}$ & 1.8 & $35 \cdot 4^{\mathrm{a}}$ & 2.0 & $35 \cdot 4^{\mathrm{a}}$ & 1.7 & $34 \cdot 2^{a, b}$ & 1.2 & $33 \cdot 7^{\mathrm{b}}$ & 1.2 & $34 \cdot 2^{a, b}$ & 1.8 & $<0.001$ & 0.004 \\
\hline \multirow{2}{*}{\multicolumn{15}{|c|}{ 2-year anthropometry }} \\
\hline & & & & & & & & & & & & & & \\
\hline Weight $(\mathrm{kg})$ & $13 \cdot 4^{b, c}$ & $2 \cdot 2$ & $14 \cdot 1^{\mathrm{a}, \mathrm{b}}$ & $2 \cdot 0$ & $14.9^{\mathrm{a}}$ & $2 \cdot 3$ & $12 \cdot 6^{\mathrm{c}}$ & 1.2 & $12 \cdot 7^{b, c}$ & 1.5 & $13 \cdot 0^{b, c}$ & 1.8 & $<0.0001$ & 0.02 \\
\hline Weight $z$ score & $0.90^{\mathrm{b}}$ & 1.21 & $1 \cdot 22^{a, b}$ & $1 \cdot 17$ & $1 \cdot 70^{\mathrm{a}}$ & 1.24 & $0.39^{b}$ & 0.70 & $0.44^{b}$ & 1.00 & $0.60^{\mathrm{b}}$ & 1.16 & $<0.0001$ & 0.03 \\
\hline Height $(\mathrm{cm})$ & 87.6 & 3.8 & 88.9 & 3.7 & 89.5 & 3.4 & $87 \cdot 1$ & $2 \cdot 9$ & $88 \cdot 3$ & 3.3 & $87 \cdot 3$ & $3 \cdot 7$ & 0.007 & 0.20 \\
\hline Height $z$ score & 0.30 & 1.07 & 0.54 & 1.15 & 0.68 & 1.03 & 0.01 & 0.80 & 0.35 & 0.99 & 0.11 & 0.21 & 0.04 & 0.57 \\
\hline Head circumference $(\mathrm{cm})$ & $49 \cdot 2$ & 1.7 & 49.5 & 1.6 & 49.6 & 1.7 & 48.5 & 1.3 & 47.9 & 1.4 & 49.0 & 1.7 & $<0.0001$ & 0.09 \\
\hline Head circumference $z$ score & $1.07^{\mathrm{a}}$ & 1.06 & $1 \cdot 17^{a, b}$ & 1.12 & $1.23^{a}$ & $1 \cdot 13$ & $0.46^{\mathrm{a}, \mathrm{b}}$ & 0.82 & $0.08^{\mathrm{b}}$ & 0.94 & $0.79^{\mathrm{a}, \mathrm{b}}$ & 1.07 & $<0.0001$ & 0.04 \\
\hline $\mathrm{BMI}\left(\mathrm{kg} / \mathrm{m}^{2}\right)$ & $17 \cdot 3^{\mathrm{b}}$ & 1.8 & $17 \cdot 7^{\mathrm{a}, \mathrm{b}}$ & 1.7 & $18 \cdot 5^{\mathrm{a}}$ & 2.0 & $16 \cdot 6^{\mathrm{b}}$ & 1.2 & $16 \cdot 2^{\mathrm{b}}$ & 1.5 & $16 \cdot 9^{\mathrm{b}}$ & 1.5 & $<0.0001$ & 0.005 \\
\hline BMI $z$ score & $1.02^{b}$ & 1.16 & $1 \cdot 26^{\mathrm{a}, \mathrm{b}}$ & 1.06 & $1.81^{\mathrm{a}}$ & 1.22 & $0.53^{\mathrm{b}, \mathrm{c}}$ & 0.87 & $0.27^{c}$ & 1.09 & $0.75^{\mathrm{b}, \mathrm{c}}$ & 1.03 & $<0.0001$ & 0.006 \\
\hline \multicolumn{15}{|l|}{ 2-year body composition } \\
\hline Fat mass $(\mathrm{kg})$ & 2.6 & 1.0 & $2 \cdot 8$ & 1.0 & 2.7 & $1 \cdot 2$ & $2 \cdot 3$ & 1.0 & $2 \cdot 6$ & 0.7 & $2 \cdot 6$ & 0.9 & 0.45 & 0.68 \\
\hline Fat-free mass $(\mathrm{kg})$ & $10 \cdot 6^{\mathrm{b}}$ & 1.7 & $11 \cdot 3^{a, b}$ & 1.8 & $12 \cdot 3^{\mathrm{a}}$ & $2 \cdot 1$ & $10 \cdot 1^{a, b}$ & 1.2 & $10 \cdot 1^{a, b}$ & 1.5 & $10 \cdot 4^{a, b}$ & 1.5 & $<0.0001$ & 0.03 \\
\hline Fat mass index $\left(\mathrm{kg} / \mathrm{m}^{2}\right)$ & 3.42 & 1.14 & 3.53 & 1.30 & 3.41 & 1.48 & 3.08 & 1.33 & 3.40 & 0.97 & 3.35 & 1.05 & 0.77 & 0.70 \\
\hline Fat-free mass index $\left(\mathrm{kg} / \mathrm{m}^{2}\right)$ & $13 \cdot 82^{\mathrm{a}, \mathrm{b}}$ & 1.32 & $14 \cdot 19^{a, b}$ & 1.47 & $15 \cdot 23^{\mathrm{a}}$ & 1.93 & $13 \cdot 44^{\mathrm{a}, \mathrm{b}}$ & 1.37 & $12 \cdot 98^{\mathrm{b}}$ & 1.44 & $13 \cdot 59^{\mathrm{a}, \mathrm{b}}$ & 1.27 & $<0.0001$ & 0.02 \\
\hline Fat mass:fat-free mass & 0.25 & 0.09 & 0.25 & $0 \cdot 10$ & 0.24 & 0.11 & 0.23 & 0.11 & 0.27 & 0.08 & 0.25 & 0.08 & 0.66 & 0.81 \\
\hline
\end{tabular}

NZE, New Zealand European.

a,b,c Mean values within a row with unlike superscript letters were significantly different (post hoc Tukey test).

"Ethnicity was identified by parent/caregiver at assessment and prioritised according to Ministry of Health guidelines ${ }^{23}$; Pacific includes Samoan, Cook Island Māori, Tongan and Niuean.

† Missing data at 2 years for. height (two Indian), head circunference (hree NZE, two Maori and one Indian), fat mass and lean mass (seventeen Indian, sixteen NZE, eighteen Other, eleven Pacific and three Māori).

‡ Birth data adjusted for risk factors for hypoglycaemia and maternal BMI at booking; 2-year data adjusted for birth weight $z$ score, gestation, risk factor for hypoglycaemia and maternal BMI at booking. 


\section{Relationship between birth weight and weight at 2 years}

For the overall cohort, there was a positive relationship between birth weight $z$ score and 2-year weight $z$ score, although the proportion of the variance explained by birth weight was modest $\left(R^{2} 0 \cdot 24\right.$, Fig. 1). The relationship was similar between birth weight and both BMI $\left(R^{2} 0 \cdot 14\right)$ and lean mass $\left(R^{2} 0.14\right)$ at 2 years, but there was little relationship between birth weight and FM at 2 years $\left(R^{2} 0 \cdot 05\right.$, Fig. 1).

\section{Ethnicity, body size and composition at 2 years}

At 2 years of age, after adjusting for birth weight $z$ score, gestation, risk factor for hypoglycaemia and maternal BMI at booking, Pacific children were heavier than children of all other ethnic groups except Māori, with greater BMI and BMI $z$ score. However, their FMI and FFMI were similar to those of other children, indicating that their greater weight and BMI was not due to excess adiposity (Table 3 ). Indian children had lower head circumference $z$ scores than European children and lower BMI $z$ scores but had similar FMI and FFMI.

Regression analysis showed that children of different ethnicity had different FM:FFM ratio for any given BMI (Fig. 2), with
Pacific children having lower FM:FFM for BMI and Indian children having higher FM:FFM for BMI ( $P=0 \cdot 03)$. For example, for a BMI of $16 \mathrm{~kg} / \mathrm{m}^{2}$ (50th centile for boys aged 2 years ${ }^{(26)}$ ), FM:FFM for Pacific children was 0.22 and that for Indian children was $0 \cdot 27$, a $23 \%$ difference (Fig. 2).

\section{Discussion}

There were important differences in body composition as measured by BIA at 2 years corrected age in children of different ethnic groups in this multiethnic cohort of New Zealand children.

At 2 years, Pacific children were already heavier than children in other ethnic groups, with higher BMI and BMI $z$ scores even adjusted for size at birth. The observation that Polynesian children, including Pacific children, are heavier, taller and have a higher BMI has been reported previously ${ }^{(27-29)}$, including a recent review comparing the height, weight, head circumference and BMI of children from different countries and ethnic backgrounds to WHO Multicentre Growth Reference Study reference ranges ${ }^{(30)}$. The majority of Polynesian children included in that review had BMI scores above the 90th centile (a)

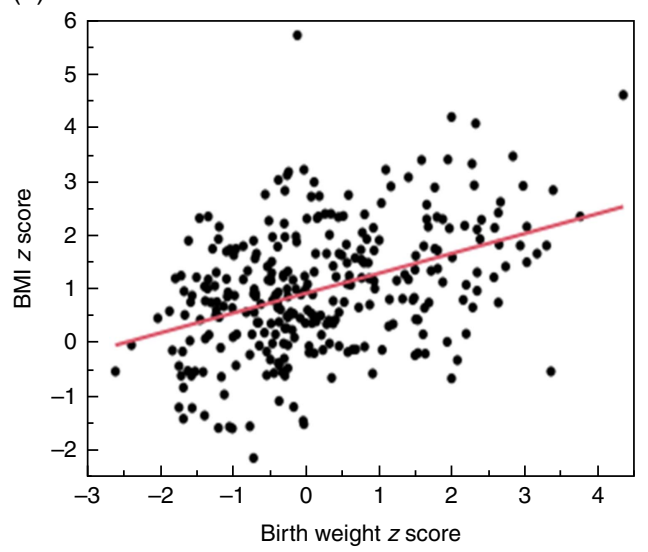

(c)

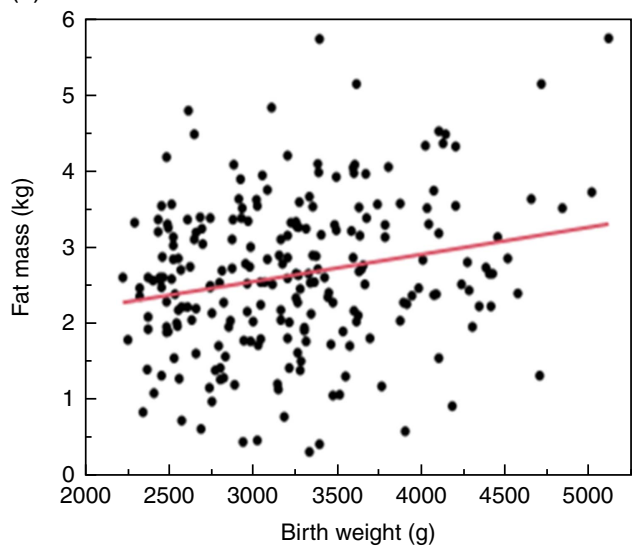

(b)

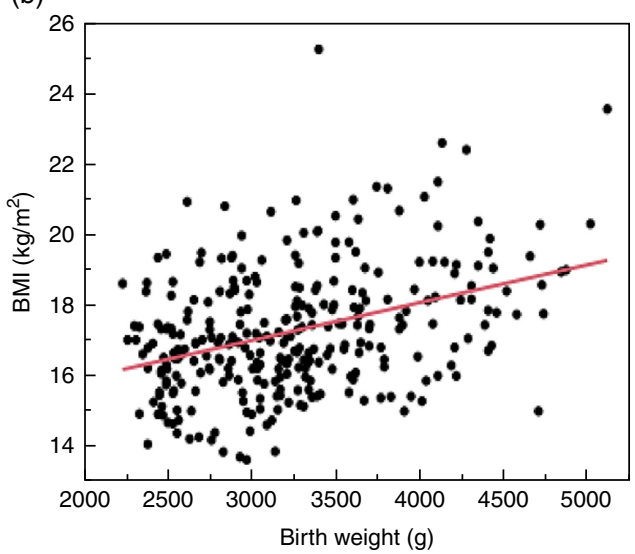

(d)

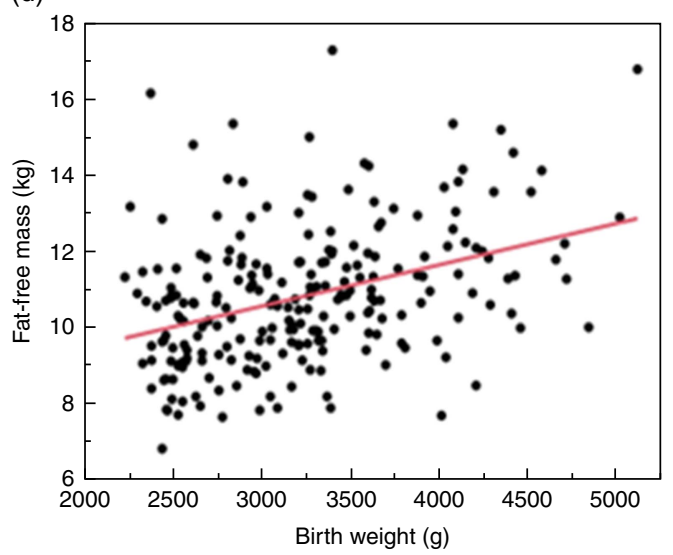

Fig. 1. Relationship between birth weight and body size at 2 years. (a) Relationship between birth weight $z$ score and BMl $z$ score at 2 years. $\beta=0.45$ (95\% $\mathrm{Cl} 0.36$, 0.54 ); $R^{2}$ 0.24; $P<0.001$. (b) Relationship between birth weight and BMl at 2 years. $\beta=0.0011$ (95\% Cl 0.0007, 0.0014 ); $R^{2} 0.14 ; P<0.001$. (c) Relationship between birth weight and fat mass at 2 years. $\beta=0.0004(95 \% \mathrm{Cl} 0.0002,0.0006) ; R^{2} 0.05 ; P<0.001$. (d) Relationship between birth weight and fat-free mass at 2 years. $\beta=0.0011(95 \% \mathrm{Cl} 0.0007,0.0014) ; R^{2} 0.14 ; P<0.001$. 


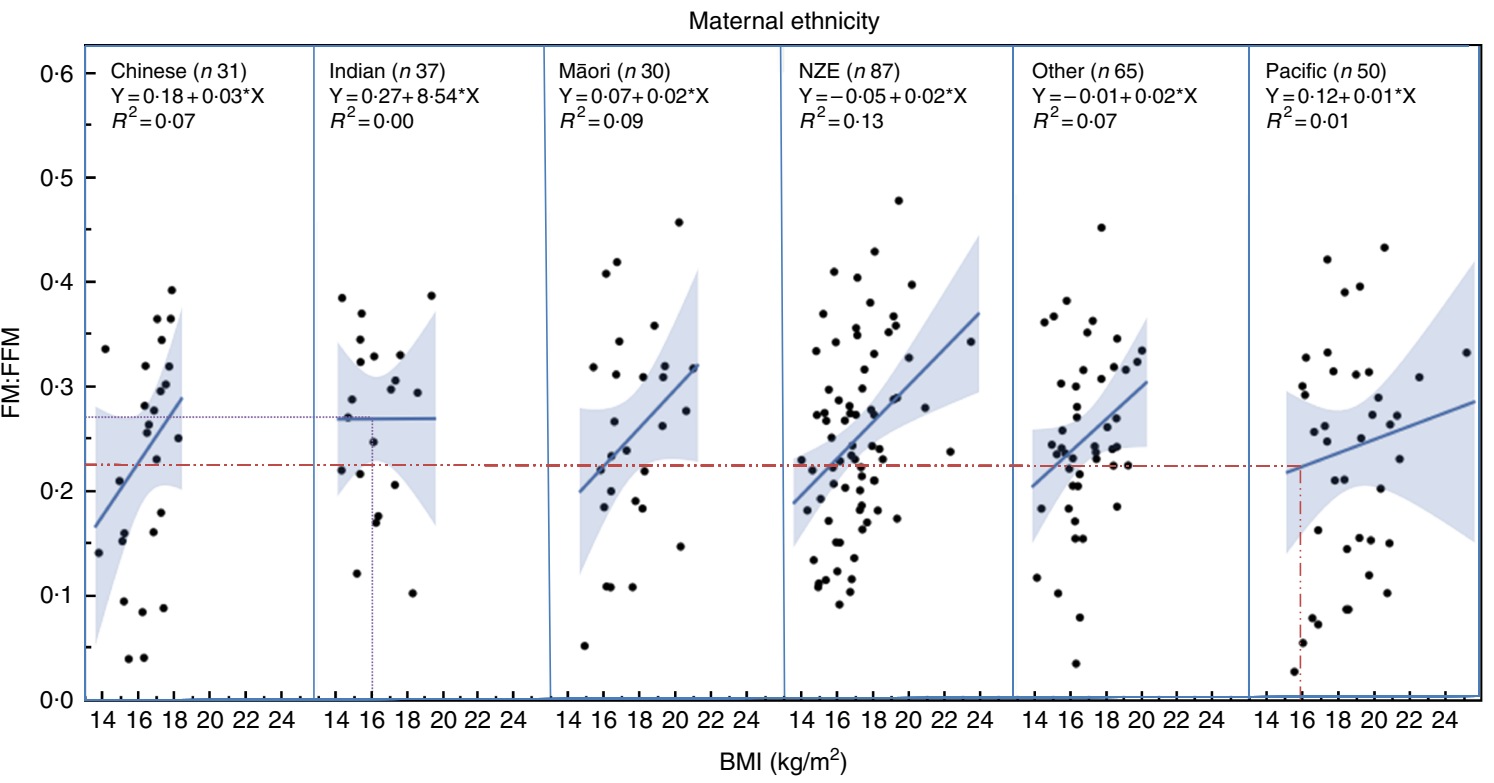

Fig. 2. Relationship between fat mass:fat-free mass (FM:FFM) and BMI in children from different ethnic groups. Lines represent regression line for each ethnicity. Dotted lines indicate the $23 \%$ difference in FM:FFM between Indian and Pacific children for a BMI of $16 \mathrm{~kg} / \mathrm{m}^{2}$ (50th centile for boys at age 2 years) ${ }^{(26)}$. NZE, New Zealand European.

based on the WHO reference ranges. The recommended WHO BMI cut-off for overweight is $>85$ th centile $(z \text { score }>1)^{(26)}$, putting most Pacific children in the overweight or obese categories. The mean BMI $z$ score for Pacific children in our study was $1.81 \mathrm{~kg} / \mathrm{m}^{2}$, and $35 / 50(70 \%)$ had BMI $z$ score $>1$, indicating that the majority of Pacific children in our cohort would also be considered overweight or obese, using the WHO criteria. Adiposity, however, was not significantly higher in the Pacific children compared with children of other ethnic groups in our cohort. Rather, Pacific children had similar FM and FFM indices to those of other children in all other ethnic groups and the lowest FM:FFM ratio at median BMI. This indicates that at least in this cohort of children, a high BMI was not a good indicator of increased adiposity across the different ethnic groups. Overweight and obesity by definition imply excessive adiposity; and therefore, in Pacific children, one should use caution when using BMI alone to identify children who are overweight and obese.

At birth, Indian children had lower birth weight and head circumference $z$ scores compared with children in other ethnic groups in this cohort, and at 2 years the smaller head circumference $z$ score persisted even after adjustment for birth size. Indian children have been shown to have different growth patterns compared with other children. For example, a study comparing anthropometry and body composition of children born in Pune, India, to that of children from Southampton, UK, showed that Indian newborns had smaller head circumference compared with European newborns; and over the first 2 years, these differences became even greater, with head circumference $z$ scores decreasing from -1.46 at birth to -2.31 at 2 years ${ }^{(8)}$. Another study showed that change in height, weight, head circumference, mid-arm circumference and growth velocity in affluent Indian children from 1 to 6 years of age were different from American and European reference ranges, indicating that perhaps there is an underlying difference in growth rate in Indian children which is not related to poverty or reduced energy intake ${ }^{(31)}$. Our data suggest that this may also apply to Indian children in New Zealand, raising the possibility that using currently accepted international standards may result in overdiagnosis of undernutrition in Indian children and underdiagnosis of overnutrition. The Indian Academy of Paediatrics recommends monitoring of height, weight and head circumference in all children for the first 3 years using locally produced reference charts when screening for under- or overnutrition $^{(32)}$. Caution should be used when using WHO growth references for assessing nutritional status in Indian children in other settings as well.

Indian children in our study also had low BMI $z$ score compared with children in the other ethnic groups, but similar FM and FFM indices, and had the highest FM:FFM at median BMI. These findings are similar to that of a previous study which investigated body composition in children of mothers with diabetes using a dual-energy X-ray absorptiometry scan and showed that Indian boys aged between 1 and 3 years had significantly less total lean mass adjusted for height compared with New Zealand European boys ${ }^{(9)}$. Others have shown similar differences in body composition at birth and in early childhood in Indian children in India and in comparison with European children ${ }^{33-36)}$. This conservation of adipose tissue despite the overall smaller size is in keeping with the 'thin-fat' phenotype of Indian infants and children, compared with their European counterparts ${ }^{(8)}$. In view of these differences in adiposity in Indian children and the relationship between adiposity and long-term adverse health outcomes ${ }^{(37)}$, a lower cut-off for waist circumference and BMI has been suggested to help better identify overweight and obese Indian children ${ }^{(38)}$. Our finding of higher FM:FFM for BMI in Indian children compared with children of other ethnicities in this New Zealand born cohort would support similar recommendations for Indian children in New Zealand. 


\section{Limitations of the study}

Our study has a number of limitations. This study reports findings from a group of children with risk factors for neonatal hypoglycaemia and therefore may not be generalisable to all children. We had a good mix of different ethnicities in our sample. 2-year-old children are not easy to engage in assessments of body composition; and despite our best efforts, we had missing data on FM and FFM for 69 (23\%) of 300 children. BIA is a portable and relatively easy-to-use device for measurement of FM and FFM in children. However, BIA does not directly measure FM and FFM, relying instead on formulae to derive these values from total body weight and total body water measurements. The constant state of hydration necessary for accurate assessment of body composition was not possible to achieve in 2-year-old children. We attempted to standardise the body composition measurements by following the same sequence and measurement technique, so all children were measured in relatively similar conditions.

\section{Conclusions}

BMI is not a good indicator of adiposity in this multi-ethnic cohort of New Zealand 2-year-old children. Pacific children have high BMI with higher proportionate lean mass, and Indian children have low BMI with higher proportionate FM. BMIbased criteria for overweight and obesity should take ethnicity into consideration in an ethnically diverse population.

\section{Acknowledgements}

\section{The hPOD Study Team are:}

Steering group: Jane E. Harding (Chair), Jane M. Alsweiler (Department of Paediatrics: Child and Youth Health, University of Auckland), Richard Edlin (School of Population Health, University of Auckland), Greg Gamble (Liggins Institute, University of Auckland), Joanne Hegarty (Newborn Services, National Women's Health, Auckland City Hospital), Christopher J. D. McKinlay (Liggins Institute, University of Auckland), Benjamin Thompson (Optometry and Vision Science, University of Waterloo) and Trecia A. Wouldes (Department of Psychological Medicine, University of Auckland).

Study team: Mariam Buksh, Nataliia Burakevych, Kelly Fredell, Karen Frost, Rashedul Hasan, Safayet Hossin, Anushika Kendaragama, Christopher McKinlay, Grace McKnight, Jenny Rogers, Nina Slabkevich, Heather Stewart, Jason Turuwhenua, Alena Vasilenko, Jess Wilson.

The authors would like to thank all the children and their families who took part in this study.

This study has been funded by the Health Research Council of New Zealand (15-216); Cure Kids (3561); Gravida (SCH-1414 Hegarty); Lottery Health Research (241266) and philanthropic donations to the University of Auckland Foundation (F-ILG-LRSR). The first author received a Gravida (National Centre for Growth and Development) scholarship.

J. Harding conceived, planned and designed the pre-hPOD dosing study and the 2-year follow-up study and secured funding for the study. J. Harding reviewed and edited the manuscript. M. B. helped plan and conduct the follow-up study, performed the statistical analysis and wrote the first draft of the manuscript. J. Hegarty helped plan and conduct the pre-hPOD study and the follow-up study. R. G. contributed to conducting the follow-up assessments. J. A. and C. M. helped plan, design and conduct the pre-hPOD and the 2-year follow-up studies. All authors contributed to editing of the manuscript and have reviewed and approved the final manuscript for submission.

The authors have no conflict of interest to declare.

\section{References}

1. Must A, Spadano J, Coakley EH, et al. (1999) The disease burden associated with overweight and obesity. JAMA 282, 1523-1529.

2. Cole TJ \& Lobstein T (2012) Extended international (IOTF) body mass index cut-offs for thinness, overweight and obesity. Pediatr Obes 7, 284-294.

3. Barlow SE (2007) Expert committee recommendations regarding the prevention, assessment, and treatment of child and adolescent overweight and obesity: summary report. Pediatrics 120, Suppl. 4, S164-S192.

4. Shear CL, Freedman DS, Burke GL, et al. (1987) Body fat patterning and blood pressure in children and young adults. The Bogalusa Heart Study. Hypertension 9, 236-244.

5. Freedman DS, Srinivasan SR, Harsha DW, et al. (1989) Relation of body fat patterning to lipid and lipoprotein concentrations in children and adolescents: the Bogalusa Heart Study. Am J Clin Nutr 50, 930-939.

6. Freedman DS \& Sherry B (2009) The validity of BMI as an indicator of body fatness and risk among children. Pediatrics 124, Suppl. 1, S23-S34.

7. Stanfield KM, Wells JC, Fewtrell MS, et al. (2012) Differences in body composition between infants of South Asian and European ancestry: the London Mother and Baby Study. Int $J$ Epidemiol 41, 1409-1418.

8. D'Angelo S, Yajnik C, Kumaran K, et al. (2015) Body size and body composition: a comparison of children in India and the UK through infancy and early childhood. J Epidemiol Community Health 69, 1147-1153.

9. Rush EC, Obolonkin V, Battin M, et al. (2015) Body composition in offspring of New Zealand women: ethnic and gender differences at age 1-3 years in 2005-2009. Ann Hum Biol 42, 498-503.

10. Ong KK (2006) Size at birth, postnatal growth and risk of obesity. Horm Res Paediatr 65, Suppl. 3, 65-69.

11. Simmonds M, Llewellyn A, Owen CG, et al. (2016) Predicting adult obesity from childhood obesity: a systematic review and meta-analysis. Obes Rev 17, 95-107.

12. Schellong K, Schulz S, Harder T, et al. (2012) Birth weight and long-term overweight risk: systematic review and a metaanalysis including 643902 persons from 66 studies and 26 countries globally. PLOS ONE 7, 1-12.

13. Armitage JA, Poston L \& Taylor PD (2008) Developmental origins of obesity and the metabolic syndrome: the role of maternal obesity. Obes Metab 36, 73-84.

14. Moser K, Stanfield KM \& Leon DA (2008) Birthweight and gestational age by ethnic group, England and Wales 2005: introducing new data on births. Health Stat $Q$ 39, 22-31.

15. Shiono PH, Klebanoff MA, Graubard BI, et al. (1986) Birth weight among women of different ethnic groups. JAMA $\mathbf{2 5 5}$, $48-52$.

16. Leon DA \& Moser KA (2012) Low birth weight persists in South Asian babies born in England and Wales regardless of 
maternal country of birth. Slow pace of acculturation, physiological constraint or both? Analysis of routine data. J Epidemiol Community Health 66, 544-551.

17. Statistics New Zealand (2013) Census QuickStats about a place: Auckland Region. http://archive.stats.govt.nz/Census/2013census/profile-and-summary-reports/quickstats-about-a-place. aspx?request_value $=13170 \&$ tabname $=($ accessed June 2017) .

18. Hegarty JE, Harding JE, Gamble GD, et al. (2016) Prophylactic oral dextrose gel for newborn babies at risk of neonatal hypoglycaemia: a randomised controlled dose-finding trial (the Pre-hPOD Study). PLoS Med 13, e1002155.

19. Ministry of Health Manatu Hauora (2015) Growth Charts. Wellington, New Zealand. https://www.health.govt.nz/ourwork/life-stages/child-health/well-child-tamariki-ora-services/ growth-charts (accessed June 2017).

20. Brantlov S, Ward LC, Jødal L, et al. (2017) Critical factors and their impact on bioelectrical impedance analysis in children: a review. J Med Eng Technol 41, 22-35.

21. Rowan JA, Rush EC, Obolonkin V, et al. (2011) Metformin in gestational diabetes: the offspring follow-up (MiG TOFU). Body composition at 2 years of age. Diabetes Care $\mathbf{3 4}$, 2279-2284.

22. Wells JCK, Fuller NJ, Dewit O, et al. (1999) Four-component model of body composition in children: density and hydration of fat-free mass and comparison with simpler models. Am J Clin Nutr 69, 904-912.

23. Poutasi K (2004) Ethnicity Data Protocols for the Health and Disability Sector. Wellington, New Zealand: Ministry of Health.

24. Salmond CE \& Crampton P (2012) Development of New Zealand's deprivation index (NZDep) and its uptake as a national policy tool. Can J Public Health 103, S7-S11.

25. Atkinson J, Salmond C \& Crampton P (2014) NZDep2013 Index of Deprivation. Wellington, New Zealand: Department of Public Health, University of Otago.

26. World Health Organization (2006) WHO Child Growth Standards: Length/height-for-age, Weight-for age, Weight-forlength, Weight-for-height and Body Mass Index-for-age:
Methods and Development. Geneva: World Health Organization.

27. Grant AM, Ferguson EL, Toafa V, et al. (2004) Dietary factors are not associated with high levels of obesity in New Zealand Pacific preschool children. J Nutr 134, 2561-2565.

28. Rush E, Gao W, Funaki-Tahifote M, et al. (2010) Birth weight and growth trajectory to six years in Pacific children. Int $J$ Pediatr Obes 5, 192-199.

29. Rush EC, Paterson J, Obolonkin VV, et al. (2007) Application of the 2006 WHO growth standard from birth to 4 years to Pacific Island children. Int J Obes 32, 567-572.

30. Natale V \& Rajagopalan A (2014) Worldwide variation in human growth and the World Health Organization growth standards: a systematic review. BMJ Open 4, e003735.

31. Agarwal DK \& Agarwal KN (1994) Physical growth in Indian affluent children (birth-6 years). Indian Pediatr 31, 377-413.

32. Khadilkar VV, Khadilkar AV, Choudhury P, et al. (2007) IAP growth monitoring guidelines for children from birth to 18 years. Indian Pediatr 44, 187-197.

33. Joglekar CV, Fall CHD, Deshpande VU, et al. (2007) Newborn size, infant and childhood growth, and body composition and cardiovascular disease risk factors at the age of 6 years: the Pune Maternal Nutrition Study. Int J Obes 31, 1534-1544.

34. Yajnik C (2000) Interactions of perturbations in intrauterine growth and growth during childhood on the risk of adultonset disease. Proc Nutr Soc 59, 257-265.

35. Yajnik CS, Fall CHD, Vaidya U, et al. (1995) Fetal growth and glucose and insulin metabolism in four-year-old Indian children. Diabet Med 12, 330-336.

36. Yajnik CS, Fall CHD, Coyaji KJ, et al. (2003) Neonatal anthropometry: the thin-fat Indian baby. The Pune Maternal Nutrition Study. Int J Obes Relat Metab Disord 27, 173-180.

37. Wells JCK, Pomeroy E, Walimbe SR, et al. (2016) The elevated susceptibility to diabetes in India: an evolutionary perspective. Front Public Health 4, 145.

38. Virani N (2011) Reference curves and cut-off values for anthropometric indices of adiposity of affluent Asian Indian children aged 3-18 years. Ann Hum Biol 38, 165-174. 